\title{
Adherence, Adverse Drug Reaction and Effectiveness of the Hepatitis C Chronic Treatment
}

\author{
Karin Schwambach ${ }^{1}$, Carine Raquel Blatt ${ }^{2}$
}

\begin{abstract}
This text seeks to assess adherence, adverse drug reaction and Sustained Virological Response (SVR) in the therapy for hepatitis C. This follow-up retrospective observational study was conducted in a specialized center for hepatitis treatment in Southern Brazil. This research included 257 patients under hepatitis $C$ treatment with all oral direct acting antivirals in a clinical setting from March to August 2016. The data was obtained from medical records. Adherence was measured by medicines refill and Medication Possession Ratio. Of the 253 patients evaluated, 8,7\% had some problem with adherence to the treatment. No cases of treatment discontinuation due to adverse drug reaction was observed. However, 1433 adverse drug reactions were identified and classified as mild, with an average of 5,6 per patient. The most frequent reactions were headache $(55,7 \%)$, asthenia $(47,3 \%)$, altered appetite $(41,9 \%)$, dry skin $(37,2 \%)$, and nausea/vomiting $(35,9 \%)$. The overall SVR rate was $90,9 \%$. Other outcomes were no response to treatment $(2,0 \%)$, relapsed $(2,0 \%)$, dead $(0,4 \%)$, dropout $(0,4 \%)$ and lost to follow-up $(4,3 \%)$. In the multivariate analysis, hepatitis $C$ virus and human immunodeficiency virus co-infection and longer treatment time were associated with higher SVR ( $p=0,028$ and $p=0,020$, respectively). The treatments evaluated have high response rate and were well tolerated by the patients. Adherence to treatment proved to be adequate and contributed to the results. The care offered in a specialized center provides the appropriate management of the patients' needs, contributing thus to a successful therapy.
\end{abstract}

Keywords: Chronic hepatitis C. Medication adherence. Pharmaceutical care. Drug-related side effects and adverse reactions.

ADESÃO, REAÇÕES ADVERSAS A MEDICAMENTOS E EFETIVIDADE DO TRATAMENTO DA HEPATITE C CRÔNICA

\section{RESUMO}

Este texto busca avaliar adesão, reações adversas a medicamentos e resposta virológica sustentada (RVS) na terapia para hepatite C. Este estudo observacional retrospectivo foi realizado em um centro especializado em tratamento de hepatite no sul do Brasil. Esta pesquisa incluiu 257 pacientes em tratamento de hepatite C com antivirais de ação direta orais em ambulatório clínico de março a agosto de 2016. Os dados foram obtidos em prontuários médicos. A adesão foi medida por recarga de medicamentos e relação de posse de medicamentos. Dos 253 pacientes avaliados, 8,7\% apresentaram algum problema de adesão ao tratamento. Não foram observados casos de descontinuação do tratamento por reações adversas aos medicamentos. Reações adversas a medicamentos, em número de 1.433, no entanto, foram identificadas e classificadas como leves, com média de 5,6 por paciente. As reações mais frequentes foram cefaleia $(55,7 \%)$, astenia $(47,3 \%)$, alteração de apetite $(41,9 \%)$, pele seca $(37,2 \%)$ e náusea/vômito $(35,9 \%)$. A taxa global de RVS foi de $90,9 \%$. Outros desfechos foram não resposta ao tratamento $(2,0 \%)$, recidiva $(2,0 \%)$, morte $(0,4 \%)$, abandono $(0,4 \%)$ e perda no seguimento $(4,3 \%)$. Na análise multivariada, coinfecção pelo vírus da hepatite $C$ e vírus da imunodeficiência humana e maior tempo de tratamento, foram associados a maior RVS ( $p=0,028$ e $p=0,020$, respectivamente). Os tratamentos avaliados apresentam alta taxa de resposta e foram bem tolerados pelos pacientes. A adesão ao tratamento mostrou-se adequada e contribuiu para os resultados. $\mathrm{O}$ atendimento oferecido em um centro especializado fornece o gerenciamento adequado das necessidades dos pacientes, contribuindo para uma terapia bem-sucedida.

Palavras-chave: Hepatite $\mathrm{C}$ crônica. Adesão à medicação. Assistência farmacêutica. Efeitos colaterais e reações adversas relacionados a medicamentos. 


\section{INTRODUCTION}

In 2016, the World Health Organization (WHO) released a document, signed by the Brazilian government, establishing global strategies to eliminate viral hepatitis as a public health problem by 2030 , reducing new cases by $90 \%$ and associated mortality by $65 \%$ (WHO, 2018a). In this sense, access and adherence to hepatitis $C$ treatment are important to achieve these goals.

Adherence involves interrelated aspects, such as social and economic factors, the healthcare teams and system, characteristics of the disease, therapies, and patient-related factors (WHO, 2003). A multidisciplinary approach is essential to promote comprehensive patient care and adequate adherence to treatment (BRASIL, 2015).

The medicines to treat hepatitis $\mathrm{C}$ - interferon, ribavirin, peginterferon and the first-generation direct-acting antivirals (DAAs) (boceprevir and telaprevir) - caused frequent and severe adverse effects. Due to these adverse reactions, the dropout rates are high, contributing to lower effectiveness rates (CLEO STUDY GROUP et al., 2016; GOMES et al., 2018; MIOTTO et al., 2016; WEHMEYER et al., 2014).

In Brazil, the treatment for chronic hepatitis $C$ is available in the public health system, and the guidelines are periodically reviewed. In 2015, for instance, three new DAAs were incorporated to the Brazilian Unified Health System (SUS) (BRASIL, 2015).

Second-generation DAAs in pre-marketing studies are associated with less severe adverse effects than those described in previous treatments for chronic hepatitis C (SCAVONE et al., 2016). Real-life studies reported fatigue, headache, insomnia, pruritus, photosensitivity, nausea, and diarrhea (SCAVONE et al., 2016) as the most common adverse drug reaction (ADR), and only $1-2 \%$ dropout patients due to adverse drug effects (BANSAL, 2015; SCAVONE et al., 2016). Clinical pharmacists can promote preventive measures and training to reduce hepatitis $\mathrm{C}$ virus ( $\mathrm{HCV}$ ) transmission by improving medication adherence, monitoring clinical effects, and recommending strategies to minimize $A D R s$ and drug interactions (CHAMORRO-DE-VEGA et al., 2017; MOHAMMAD et al., 2014).

The objective of this study is to assess adherence, adverse drug reaction and Sustained Virological Response (SVR) to hepatitis C therapy in a specialized center in Southern Brazil.

\section{METHODS}

A retrospective cohort was performed in a Health Care Service (in Porto Alegre, Brazil) specialized in the treatment for viral hepatitis. This service has a multidisciplinary team composed of physician, nurse, phychologist and clinical pharmacist.
All patients must participate in a pre-treatment group meeting conducted by a psychologist or nurse before starting the treatment. The aim is to provide information about the therapy and discuss the importance of medication adherence. Then the clinical pharmacist schedules an appointment with the patient to begin the therapy. During this first appointment with the patient, the clinical pharmacist discusses the importance of medication adherence, what to do in the case of a missed dose, medication storage, management of potential adverse effects (AE), possible drug-drug interaction (DDI) with prescription and over-the-counter medicines (OTC), laboratory monitoring, and likelihood of hepatitis $C$ cure. During the treatment, the pharmacist appointment is held once a month, and the drugs are provided for 30 days. A service telephone number is also provided for patients in case of doubt or incidents.

The sample was not probabilistic and was composed of 257 patients living in Porto Alegre. All patients who began the treatment for hepatitis $C$ between March and August 2016 were included - normally, they are referred to the service by the primary healthcare unit, after the disease diagnosis. Drugs to treat chronic HCV are sofosbuvir (SOF)-based direct-acting antivirals (DAAs), simeprevir (SIM) and daclatasvir (DAC), in different associations, according to the current guideline (BRASIL, 2015).

The data were obtained from medical records, and the variables collected were sex, age, virus genotype, rate of liver fibrosis (as determined by liver biopsy, elastography, fibrotest, APRI or FIB4 scores), drug regimen used in the treatment for hepatitis, $\mathrm{Hu}$ man immunodeficiency virus (HIV)-HCV co-infection, previous hepatitis $C$ treatment, and treatment duration. The main outcomes measured were Sustained Virological Response (SVR), relapse, no response, adverse drug reaction and adherence.

The effectiveness was defined by SVR at week 12 post-treatment. This response was defined as a $\mathrm{HCV}$ viral load lower than $15 \mathrm{UI} / \mathrm{mL}$. HCV ribo-nucleic acid (RNA) levels were measured using the real-time transcriptase-kPCR assay; when the virus RNA was undetectable at the end of treatment, but detectable three months after the patients had relapsed. Nonresponders were those who showed positive HCV-RNA at the end of treatment. Moreover, the outcomes were analyzed based on all patients who started the hepatites $C$ treatment with DAAs (intention to treat ITT). Patients who did not return to the service at the end of the follow-up period were classified as lost of follow-up. 
Adverse drug reactions were recorded in a specific form by the pharmacist or nurse during patient follow-up. The most common adverse reactions were listed, and patients asked about changes in their health status after starting the treatment and in the period between appointments.

The classification of the ADR frequency was based on the following criteria: very common (more than 10\%), common (1 to $10 \%)$, uncommon (0.1 to $1 \%)$, and rare $(0,01$ to $0,1 \%)$ (UPPSALA..., 2018). ADRs were also categorized according to severity, following the WHO's terminology (UPPSALA..., 2018): mild, reactions with little clinical importance and short duration that may require treatment, without substantially affecting the patient's life; moderate are those that may alter the patient's usual activities, resulting in temporary incapacity, without consequences and need for intervention; serious, reaction that results in death, requires or prolongs hospital admission, causes persistent or significant disability or incapacity, and life-threatening condition.

Pill count is an indirect measure to calculate the number of dosage units taken between two scheduled appointments or clinic visits. Medication Possession Ratio (MPR) or Pharmacy Dispensing Records (PDR) indicates the days' supply obtained per refill interval. Knowing the treatment regimen of each drug, the adherence was evaluated according to the medication the patient received from the pharmacy department. The dispensing dates and units dispensed were also considered. This measures were evaluated through manual counting of remaining medications and compared with the prescribed regimen to check agreement between the number of drugs received and the number used (CAMPOS FERNÁNDEZ DE SEVILLA et al., 2019; LAM; FRESCO, 2015).

Statistical analysis was conducted using Statistical Package for Social Science (SPSS software version 23). Tests were two-sided and type I error was set at 0,05 . Descriptive statistics were performed with all available data. The association between SVR and a set of potential explanatory variables were analyzed by Poisson regression. The variables with $p<0.20$ in the univariate analysis were included in the multivariate analysis. Estimates of relative risk (RR) were also obtained with 95\% confidence interval $(\mathrm{Cl})$, and the average of ADRs per patient according to treatment regimens were compared with Kruskal-Wallis test and with Dunn's test.

All procedures involving human participants were approved by the Research Ethics Committee of the Federal University of Health Sciences of Porto Alegre and by the Ethics Committee of the Presidente Vargas Maternal and Child Hospital, under opinion number 1899407.

\section{RESULTS}

This study evaluated the medical records of 257 patients. Two patients were excluded for choosing another treatment center, and two patients under treatment were transferred to another center, totaling 253 patients. Most of them (66,8\%) carried the genotype $1,28,4 \%$ carried the genotype 3 . Three individuals had more than one HCV genotype. Regarding the stage of liver fibrosis, $62,0 \%$ had cirrhosis. The mean age of the patients was 58,7 years old (SD $=9,6$ ). Those who were under treatment for 24 weeks had previously received telaprevir or boceprevir, except for two patients who had advanced cirrhosis, according to current protocols. Six different drug combinations were analyzed, all based on sofosbuvir (SOF). Table 1 shows the characteristics of the patients and hepatitis $C$ treatment.

Table 1 - Characteristics of patients who underwent hepatitis $C$ treatment carried out in a specialized center, between March and August 2016. Porto Alegre (RS), Brazil $(n=253)$

\begin{tabular}{lcc}
\hline Patients' characteristics & $\mathbf{n}$ & $\%$ \\
\hline Age ( $\geq 60$ years) & 119 & 47,0 \\
Men & 135 & 53,4 \\
Presence of cirrhosis & 157 & 62,1 \\
HCV Genotype & & \\
1 & 169 & 66,8 \\
2 & 8 & 3,2 \\
3 & 72 & 28,4 \\
4 & 1 & 0,4 \\
1,3 & 2 & 0,8 \\
3,4 & 1 & 0,4 \\
Treatment naive & 99 & 39,1 \\
Co-infected with HIV & 20 & 7,9 \\
Hepatitis C Treatment & & \\
SOF + DAC + R & 136 & 53,8 \\
SOF+DAC & 69 & 27,2 \\
SOF + PEG + R & 21 & 8,3 \\
SOF + R & 9 & 3,6 \\
SOF + SIM & 9 & 3,6 \\
SOF + SIM + R & 9 & 3,6 \\
Treatment duration & & \\
12 weeks & 238 & 94,1 \\
24 weeks & 15 & 5,9 \\
Use of Ribavirin & 175 & 69,2 \\
Use of Peginterferon & 21 & 8,3 \\
\hline
\end{tabular}

$\mathrm{HCV}=$ Hepatitis C virus; HIV = Human immunodeficiency virus; SOF + DAC = sofosbuvir and daclatasvir; SOF $+\mathrm{DAC}+\mathrm{R}=$ sofosbuvir, daclatasvir and ribavirin; SOF + PEG + R=sofosbuvir, peginterferon alfa and ribavirin; SOF + $\mathrm{R}=$ sofosbuvir and ribavirin; SOF + SIM = sofosbuvir and simeprevir; SOF + $\mathrm{SIM}+\mathrm{R}=$ sofosbuvir, simeprevir and ribavirin

Source: Prepared by the authors. 
Regarding treatment outcome, $90,9 \%$ of the patients achieved SVR (according to the intention-to-treat analysis). Other outcomes were no response to treatment $(2,0 \%)$, relapsed $(2,0 \%)$, dead $(0,4 \%)$, voluntarily dropout $(0,4 \%)$ and lost to follow-up $(4,3 \%)$.

In the group of patients who did not achieve SVR, five did not respond to the treatment, five relapsed, and one dropped out due to personal reasons. In this group, two patients were referred to other services after the diagnosis of hepatocellular carcinoma (HCC).

The univariate analysis showed a statistically significant association between co-infection, treatment duration and use of ribavirin with SVR. In the adjusted analysis for these variables, co-infection and longer treatment time were associated with higher SVR ( $p=0,028$ and $p=0,02$, respectively) (Table 2). None of the other variables analyzed showed a statistical significant association with the outcome in the analysis.

Regarding ADRs, $88,5 \%$ of the 253 patients reported at least one reaction. Table 3 presents the results of ADRs identified and mean per patient, ac- cording to the treatment regimens. The comparison between means showed SOF+SIM had less ADRs than $S O F+D A C+R \quad(p=0,037)$ and SOF+PEG+R $(p<0,001)$. SOF+DAC had less ADRs than SOF+PEG $+R(p=0,001)$, and $S O F+D A C+R$ had less $A D R$ than $S O F+P E G+R$ $(p=0,036)$.

Table 3 - Number and mean of ADRs per patient according Hepatitis $C$ treatment prescription profile

\begin{tabular}{|lccc|}
\hline \multirow{2}{*}{$\begin{array}{l}\text { Hepatitis C } \\
\text { Treatment Regim }\end{array}$} & $\begin{array}{c}\text { Number of } \\
\text { patients }\end{array}$ & \multicolumn{2}{c|}{ Adverse Drug Reaction } \\
\cline { 3 - 4 } & 21 & $\mathbf{n}$ & Mean \\
\hline SOF+PEG+R & 9 & 64 & 9,4 \\
SOF+R & 136 & 793 & 7,1 \\
SOF+DAC+R & 9 & 47 & 5,8 \\
SOF+SIM+R & 69 & 314 & 5,2 \\
SOF+DAC & 9 & 17 & 4,5 \\
SOF+SIM & 253 & 1433 & 5,6 \\
\hline Total & &
\end{tabular}

SOF + DAC = sofosbuvir and daclatasvir; SOF + DAC + R = sofosbuvir, daclatasvir and ribavirin; SOF + PEG $+\mathrm{R}=$ sofosbuvir, peginterferon alfa and ribavirin; SOF $+\mathrm{R}=$ sofosbuvir and ribavirin; SOF $+\mathrm{SIM}=$ sofosbuvir and simeprevir; SOF + SIM + R = sofosbuvir, simeprevir and ribavirin. Source:

Table 2 - Multivariate analysis of basis characteristics and SVR for patients attended at a specialized center, between March and August 2016. Porto Alegre (RS), Brazil ( $n=242)$

\begin{tabular}{|c|c|c|c|c|}
\hline Variables & $\mathbf{n}$ & $\begin{array}{c}\text { SVR } \\
\text { n (\%) }\end{array}$ & $\begin{array}{c}\text { RR } \\
(95 \% \mathrm{Cl})\end{array}$ & $\begin{array}{c}\text { Adjusted RR } \\
(95 \% \mathrm{Cl})\end{array}$ \\
\hline \multicolumn{5}{|l|}{ Age group } \\
\hline$<60$ years & 128 & $122(95,3)$ & 1 & \\
\hline$\geq 60$ years & 114 & $108(94,7)$ & $0,994(0,94-1,05)$ & \\
\hline \multicolumn{5}{|l|}{ Gender } \\
\hline Male & 131 & $107(96,4)$ & 1 & \\
\hline Female & 111 & $123(93,7)$ & $1,03(0,97-1,09)$ & \\
\hline \multicolumn{5}{|c|}{ Presence of cirrhosis } \\
\hline Yes & 144 & $144(94,7)$ & 1 & \\
\hline No & 90 & $86(95,6)$ & $1,01(0,95-1,07)$ & \\
\hline \multicolumn{5}{|l|}{ HCV Genotype } \\
\hline 3 & 69 & $62(89,9)$ & 1 & 1 \\
\hline 1 & 164 & $159(97,0)$ & $1,079(0,99-1,17)$ & $1,06(0,97-1,15)$ \\
\hline \multicolumn{5}{|c|}{ Previous treatment } \\
\hline Yes & 96 & $90(93,8)$ & 1 & \\
\hline No & 146 & $140(95,9)$ & $1,02(0,96-1,09)$ & \\
\hline \multicolumn{5}{|c|}{ Co-infected with HIV } \\
\hline Yes & 19 & $19(100)$ & 1 & 1 \\
\hline No & 223 & $211(94,6)$ & $0,95(0,92-0,98)$ & $0,97(0,94-0,99)$ \\
\hline \multicolumn{5}{|c|}{ Treatment duration } \\
\hline 12 weeks & 228 & $216(94,7)$ & 1 & 1 \\
\hline 24 weeks & 14 & $14(100)$ & $1,06(1,02-1,09)$ & $1,05(1,01-1,09)$ \\
\hline \multicolumn{5}{|c|}{ Use of Ribavirin } \\
\hline Yes & 168 & $157(93,5)$ & 1 & 1 \\
\hline No & 74 & $73(98,6)$ & $1,06(1,00-1,11)$ & $1,04(0,99-1,09)$ \\
\hline \multicolumn{5}{|c|}{ Use of Peginterferon } \\
\hline Yes & 21 & $21(100)$ & 1 & \\
\hline No & 221 & $221(100)$ & $1,12(0,94-1,34)$ & \\
\hline
\end{tabular}

SVR = sustained virological response; RR = relative risk; $\mathrm{Cl}=$ confidence interval 95\%; HCV = Hepatitis C virus; HIV = human immunodeficiency virus. Source: Prepared by the authors. 
The ADRs classified as "very common" were: headache $(55,7 \%)$, asthenia $(47,3 \%)$, change in appetite $(41,9 \%)$, dry skin $(37,2 \%)$, and nausea/vomiting $(35,9 \%)$. No rare ADRs were reported. Some reactions were classified as uncommon, such as hiccups, thirst, abnormalities in the urinary system, interrupted sleep, coryza, dyspnea, fainting, edema, hemolysis, low libido, unpleasant odor, ringing in the ears, weight, cramps, sun-sensitive skin, loss of the sense of smell, blood pressure change, cold, psoriasis, skin lesions, sweating, and local reactions.

All ADRs identified were classified as mild, and 53 patients required some sort of intervention to manage them. Of these, 32 self-medicated with analgesics, while the other 21 patients sought medical advice. No cases of discontinuation of treatment caused by ADRs were observed. Figure 1 shows the frequency of the most common adverse reactions in each hepatitis $C$ treatment regimen.

Of the 253 patients evaluated, $22(8,7 \%)$ had problems with the adherence to the treatment, $17 \mathrm{pa}$ tients reported leftover medications, and five reported lack of medication during the study period. Of these, 16 patients achieved SVR, two relapsed, and fourwere classified as lost to follow-up. All drugs received were sufficient for one month of treatment. The subsequent appointment for receiving the medicines was always scheduled so the patient would not be without medication. All activities have been recorded.

\section{DISCUSSION}

The overall SVR rate was $90,9 \%$, according to other national studies (FERREIRA et al., 2018; HOLZMANN et al., 2018; SETTE-JR et al., 2017). In the analysis by genotype, $92,9 \%$ of the carriers of genotype 1 , the most prevalent one, achieved SVR. This result was similar to a meta-analysis made in 2015 with second-generation DAAs (BANSAL, 2015), but slightly lower than other studies conducted in Brazil (FERREIRA et al., 2018; HOLZMANN et al., 2018; SETTE-JR et al., 2017), which evaluated different combinations of DAAs and showed SVR rates around 95\% in patients with HCV genotype 1.

Among the patients with genotype 3, 86,1\% achieved SVR, in line with previous studies (15-16). Genotype 3 is the second most prevalent in Brazil and, despite the lower SVR rates, the difference between the analyzed genotypes was not significant.

Figure 1 - Frequency of distribuition of ADRs classified as very common per hepatitis C treatment prescription profile

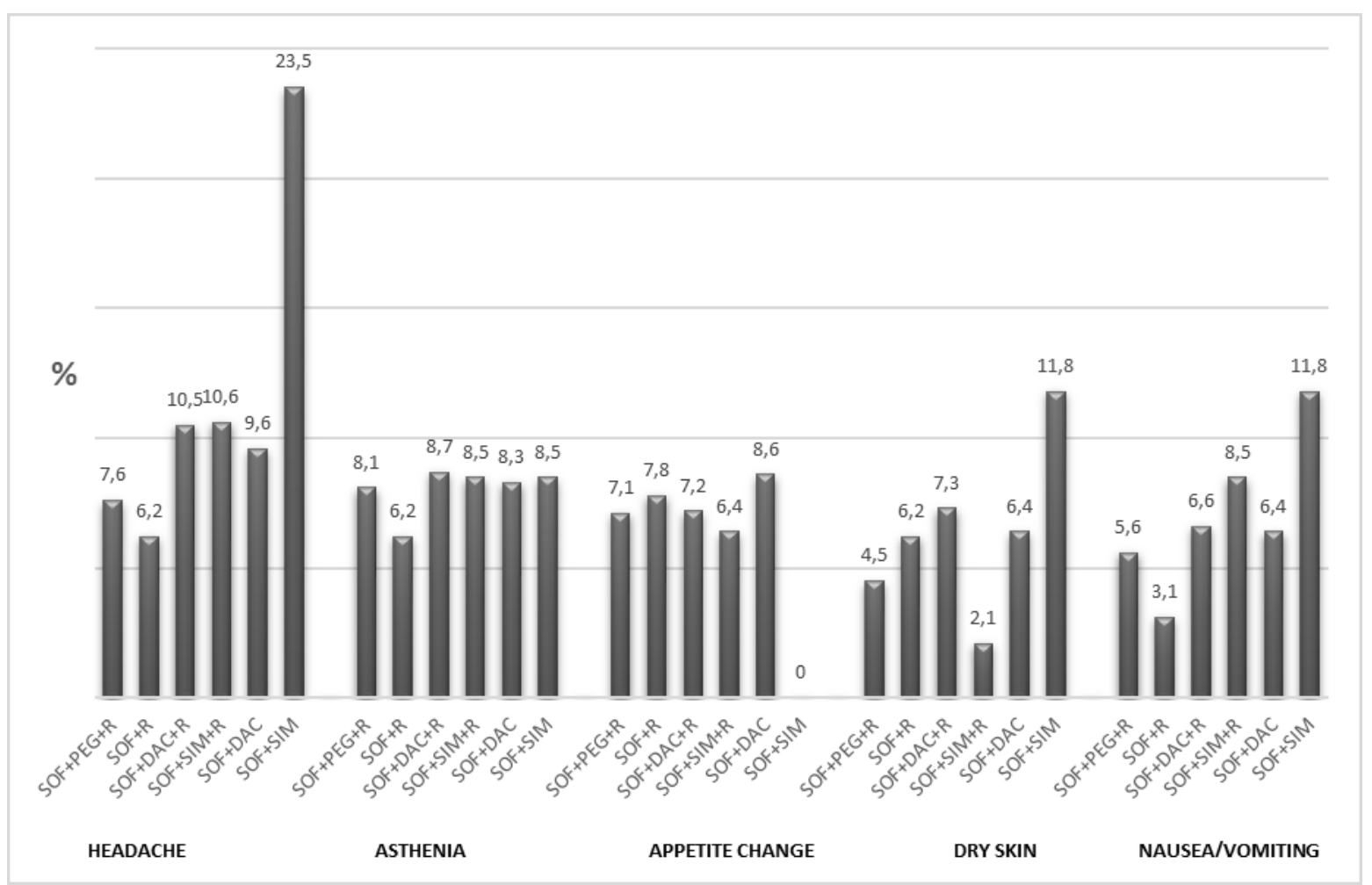

SOF + DAC = sofosbuvir and daclatasvir; SOF + DAC + R = sofosbuvir, daclatasvir and ribavirin; SOF + PEG + R = sofosbuvir, peginterferon alfa and ribavirin; SOF $+\mathrm{R}=$ sofosbuvir and ribavirin; SOF + SIM = sofosbuvir and simeprevir; SOF + SIM + R = sofosbuvir, simeprevir and ribavirin 
Despite the small number of patients co-infected with HIV-HCV in our study ( $n=20)$, none of them failed treatment. Studies indicate SVR rates are similar to individuals co-infected with HIV-HCV (ZEUZEM, 2017). In clinical practice, the potential interactions between the drugs used in both treatments must be evaluated (ZEUZEM, 2017). Patients co-infected with HIV-HCV with some degree of hepatic impairment usually get access to HCV treatment, according to current guidelines, and this factor may have influenced the outcome.

The 24-week treatment was associated with higher SVR in the multivariate analysis. Only $15 \mathrm{pa-}$ tients underwent this treatment regimen, indicating that this result should be interpreted with caution. Thirteen patients had already received previous treatment.

With the new DAAs (BRASIL, 2015), patients who were formerly ineligible for treatment due to comorbidities had access to hepatitis $\mathrm{C}$ treatment. Although DAAs are considered safe and well-tolerated (BINDA et al., 2017; WHO, 2018b), patients take other drugs, making the evaluation of all potential drug interactions more difficult (SCAVONE et al., 2016).

This fact shows the importance of prior medical counselling for the hepatitis $C$ treatment, as well as the importance of pharmaceutical evaluations throughout treatment. Once the patients' comorbidities and use of drugs are known, the team can follow the most appropriate strategy for dealing with possible clinical complications during the treatment for hepatitis C.

Regarding ADRs, $88,5 \%$ of the patients evaluated in this study reported at least one reaction, but all adverse reactions reported were classified as mild. The most frequent reactions were headache, asthenia, change in appetite, dry skin, nausea, and vomiting. The ADRs cited in our results were similar to a review on safety results of main second-generation DAAs in pivotal and post-marketing studies (SCAVONE et al., 2016). The most common ADRs for all these drugs were gastrointestinal issues, asthenia, headache, and insomnia (SCAVONE et al., 2016). Treatment regimens with SIM have resulted in cutaneous ADRs, as described in pre-marketing studies. According to other safety review studies, the most cited ADRs for the SOF + PEG + R regimen were fatigue, headache, and nausea. Ribavirin-containing regimens are associated with higher incidence of ADRs, when compared with regimens without the substance (NAPPI et al., 2017).
The ADRs found in this study are mild and can be managed with non-pharmacological measures, such as taking short walks, avoiding caffeine, and drinking water and liquids (UMAR; AKHTER; OSAMA, 2016). Safety results of pivotal and post-marketing studies showed second-generation DAAs are very well tolerated, which was expected and confirmed in our findings. Monitoring ADRs allows to improve druguse systems, and it is an important tool to promote patient safety and quality of health care (SCAVONE et al., 2016).

Regarding adherence to treatment, $8,7 \%$ of the problems were reported in the pharmaceutical appointment. The predominantly oral regimen favors adherence, but it is essential to instruct patients about the importance of adherence for a successful treatment. No data are available to determine the appropriate rate of adherence to hepatitis $C$ treatment, that is, the minimum adherence rate for an effective treatment. The Australasian Association of Hepatology released in 2016 a set of guidelines for the support to patients with hepatitis $\mathrm{C}$ using direct-acting antivirals. These guidelines may be considered for improving the actions here evaluated, since they focus on the work process (RICHMOND et al., 2016). A study in Spain analyzed three methods for measuring adherence, and concluded the PDR method was the best one to predict treatment failure. Patients with an adherence less than $66.6 \%$ as measured by this method have a high probability of not achieving SVR (CAMPOS FERNÁNDEZ DE SEVILLA et al., 2019).

Other outpatient studies of individuals under treatment for hepatitis $\mathrm{C}$ found adherence rates greater than 90\% (GOMES et al., 2019; YAMAMOTO et al., 2018). In Brazil, a cohort study conducted between 2015 and 2017 evaluated 240 patients treated by clinical pharmacists. The patients reported high levels of satisfaction with the care, good relationship with the pharmacist, counselling and education about HCV infection and therapy, motivation for adherence, and convenient access to the pharmacist (GOMES et al., 2019). In this context, the pharmacist should integrate the multidisciplinary team, contributing thus to the patients' adherence, proper management of drugs, and monitor outcomes and safety results (GOMES et al., 2019; OLEA et al., 2018; YAMAMOTO et al., 2018).

This study had some limitations, including retrospective data collection in a single care centre and non-randomization of the patient groups. We also not analysed subgroups of patients (e.g. co-infection with hepatites B virus - HBV, cirrhosis, liver transplant), because the sample size is small, considering other Bra- 
zilian studies that evaluated between 1,000 and 3,900 patients (HOLZMANN et al., 2018; LOBATO et al., 2019; MINME et al, 2018). On the other hand, all patients under treatment during the study period were included, even those co-infected with HIV and with various stages of liver failure. Our results are relevant because they reveal real-life data on patients treated in the Brazilian public health system.

The Brazilian Ministry of Health has been working on strategies to increase access to this treatment and eradicate HCV. The review of healthcare protocols aims to bring more effective and sustainable treatments, estimating the current cost and future budget impacts (MESQUITA et al., 2016). In addition to the drugs evaluated in this study, 3D drugs (combination of ombitasvir, dasabuvir, veruprevir, and ritonavir) were incorporated into the Brazilian healthcare protocol, including the association of ledipasvir and sofosbuvir, and the association of elbasvir and grazoprevir (BRASIL, 2018).

\section{CONCLUSION}

The results of this study confirm the treatments evaluated have high effectiveness prepared by the authors. rate and were well tolerated, since the ADRs described were mild. The results of effectiveness and safety were satisfactory, despite the high frequency of cirrhosis and previous treatments. Adherence to treatment proved to be adequate and contributed to the results. Thus, the care provided in this specialized centre fulfils the patients' needs, contributing to a successful therapy.

\section{DECLARATION OF INTEREST}

None to declare.

\section{ACKNOWLEDGEMENTS}

Serviço de Atendimento Especializado (SAE), pharmacist Rafael de Oliveira Nogueira, Pharmacy students Júlia Lourenço and Ingrid Schenkel Reinhardt.

\section{FUNDING}

This research did not receive any specific grant from funding agencies in the public, commercial or not-for-profit sectors.

\section{REFERENCES}

BANSAL, S. et al. Impact of all oral anti-hepatitis $C$ virus therapy: A meta-analysis. World J Hepatol, 7, n. 5, p. 806-813, Apr. 2015.
BINDA, C. et al. Toxicity and risks from drug-to-drug interactions of new antivirals for chronic hepatitis C. Eur Rev Med Pharmacol Sci, 21, n. 1 Suppl, p. 102-111, 032017.

BRASIL. Protocolo clínico e diretrizes terapêuticas para hepatite C e coinfecções. Brasília: Ministério da Saúde; Secretaria de Vigilância em Saúde; Departamento de DST, Aids e Hepatites Virais, 2015. p. 101.

BRASIL. Protocolo clínico e diretrizes terapêuticas para a hepatite C e coinfecções. Brasília: Ministério da Saúde; Secretaria de Vigilância em Saúde; Conitec, 2018. p. 108.

CAMPOS FERNÁNDEZ DE SEVILLA, M. et al. Measure of adherence to direct-acting antivirals as a predictor of the effectiveness of hepatitis C treatment. Int J Clin Pharm, Oct. 2019.

CHAMORRO-DE-VEGA, E. et al. Improving pharmacotherapy outcomes in patients with hepatitis $C$ virus infection treated with direct-acting antivirals: The GRUviC project. Int J Clin Pract, 71, n. 8, Aug. 2017.

CLEO STUDY GROUP et al. Boceprevir or telaprevir in hepatitis $C$ virus chronic infection: The Italian real life experience. World J Hepatol, 8, n. 22, p. 949-956, Aug. 2016.

FERREIRA, V. L. et al. Effectiveness and tolerability of direct-acting antivirals for chronic hepatitis $C$ patients in a Southern state of Brazil. Braz J Infect Dis, 22, n. 3, p. 186-192, 2018 May/June 2018.

GOMES, L. O. et al. Hepatitis C in Brazil: lessons learned with boceprevir and telaprevir. Rev Inst Med Trop São Paulo, 60, p. e29, 2018.

GOMES, L. O. et al. The benefits of a public pharmacist service in chronic hepattis $C$ treatment: The real-life results of sofosbuvir-based therapy. Res Social Adm Pharm,16(1), p. 48-53, Jan. 2020.

HOLZMANN, I. et al. Effectiveness of chronic hepatitis C treatment with direct-acting antivirals in the Public Health System in Brazil. Braz J Infect Dis, 22, n. 4, p. 317-322, 2018 July/Aug. 2018.

LAM, W. Y.; FRESCO, P. Medication Adherence Measures: An Overview. Biomed Res Int, p. 217.047, 2015.

LOBATO, C. M. O. et al. Direct antiviral therapy for treatment of hepatitis C: A real-world study from Brazil. Ann Hepatol, Aug. 2019.

MESQUITA, F. et al. The Brazilian comprehensive response to hepatitis $C$ : from strategic thinking to access to interferon-free therapy. BMC Public Health, 16, n. 1, p. 1.132, 11 2016.

MINME, R. et al. Profile of Patients With Chronic Hepatitis C in a Public Health Program in Southern Brazil. Arq Gastroenterol, 55, n. 4, p. 403-406, 2018 Oct./Dec. 2018.

MIOTTO, N. et al. Predictors of early treatment discontinuation and severe anemia in a Brazilian cohort of hepatitis $C$ patients treated with first-generation protease inhibitors. Braz J Med Biol Res, 49, n. 7, June 2016.

MOHAMMAD, R. A. et al. Provision of clinical pharmacist services for individuals with chronic hepatitis $C$ viral infection: Joint Opinion of the GI/Liver/Nutrition and Infectious 
Diseases Practice and Research Networks of the American College of Clinical Pharmacy. Pharmacotherapy, 34, n. 12, p. 1.341-1.354, Dec. 2014.

NAPPI, A. et al. Safety of new DAAs for chronic HCV infection in a real life experience: role of a surveillance network based on clinician and hospital pharmacist. Infect Agent Cancer, 12, p. 12, 2017.

OLEA, A. et al. Role of a clinical pharmacist as part of a multidisciplinary care team in the treatment of HCV in patients living with HIV/HCV coinfection. Integr Pharm Res Pract, 7, p. 105-111, 2018.

RICHMOND, J. A. et al. The Australasian Hepatology Association consensus guidelines for the provision of adherence support to patients with hepatitis $C$ on direct acting antivirals. Patient Prefer Adherence, 10, p. 2.479-2.489, 2016.

SCAVONE, C. et al. New era in treatment options of chronic hepatitis C: focus on safety of new direct-acting antivirals (DAAs). Expert Opin Drug Saf, 15, n. sup. 2, p. 85-100, Dec. 2016.

SETTE-JR, H. et al. Treatment of Chronic HCV Infection with the New Direct Acting Antivirals (DAA): First Report of a Real World Experience in Southern Brazil. Ann Hepatol, 16, n. 5, p. 727-733, 2017 Sep./Oct. 2017.

UMAR, M.; AKHTER, T. S.; OSAMA, M. Issues Pertaining To Daas. J Ayub Med Coll Abbottabad, 28, n. 4 Suppl 1, p. S895-S900, 2016 Oct./Dec. 2016.

UPPSALA MONITORING CENTRE. Glossary of Terms used in Pharmacovigilance. 2018. Disponível em: https://www. who-umc.org/global-pharmacovigilance/global-pharmacovigilance/glossary/.

WEHMEYER, M. H. et al. Safety and efficacy of protease inhibitor based combination therapy in a single-center "real-life" cohort of 110 patients with chronic hepatitis $C$ genotype 1 infection. BMC Gastroenterol, 14, p. 87, May 2014.

WHO. World Health Organization. Adherence to Long-Term Therapies. Evidence for Action. WHO Library Cataloguing-in-Publication, 2003. p. 211.

WHO. World Health Organization. Guidelines for the screening care and treatment of persons with chronic hepatitis $C$ infection. Geneva. 2018a. p. 108.

WHO. World Health Organization. Hepatitis C. Key facts, Fact Sheets. 2018b. Disponivel em: https://www.who.int/ news-room/fact-sheets/detail/hepatitis-c

YAMAMOTO, H. et al. Evaluation of pharmaceutical intervention in direct-acting antiviral agents for hepatitis $C$ virus infected patients in an ambulatory setting: a retrospective analysis. J Pharm Health Care Sci, 4, p. 17, 2018.

ZEUZEM, S. Treatment Options in Hepatitis C. Dtsch Arztebl Int, 114, n. 1-02, p. 11-21, Jan. 2017. 